\title{
THE ORIGIN OF OVA IN THE ADULT OPOSSUM ${ }^{1}$
}

\author{
N. B. HVERETT
}

Department of Zoology, University of Michigan, Ann Arbor

THREe PLATES (ELEVEN FIGURES)

\section{INTRODUCTION}

Within recent years many contributions have been published dealing with the problem of the origin and history of the definitive germ cells in the mammalian ovary. A number of investigators contend that the germ cells which arise previous to the time of birth are the progenitors of the definitive ova in the adult. Others believe that most, if not all, of the sex cells which are present at birth degenerate, and that the functional ova take their origin from cells of the germinal epithelium. Also, conflicting views are held by different authors concerning the time of formation of the functional ova during prepubertal and postpubertal life. Some state that definitive ova are continually formed from the germinal epithelium of the adult and they show a relation between such formation and the oestrous cycle. The source and time of origin of the definitive ova therefore still remain unanswered questions for the mammals. The present study on the opossum, Didelphys virginiana, was made to find whether ova are formed from the epithelial covering of the ovary during sexual maturity, and if so, to discover how and when they are formed. It was expected that a study of the origin of ova in a primitive form would add information regarding the manner of formation of ova in higher mammals.

\section{HISTORY}

In the literature much controversial information may be found regarding these problems. However, only a few

' Contribution from the Department of Zoology, University of Miehigan. 
opinions concerning the formation of the functional ova after birth and during sexual maturity will be mentioned here.

Arai ('20) was the first to make a modern approach to the problem. From a study of the total number of ova in the albino rat during the entire life span, he reported that the definitive oocytes begin to form from the germinal epithelium about 10 to 15 days after birth and that proliferation is most rapid from 15 to 60 days, then it gradually decreases with age.

Allen ('23), from his study of the white mouse, concluded that at each normal ocstrous period young ova were added to the cortex of the adult ovary. According to him ova arise from cells in the germinal epithelium through mitosis. He contends that if the long axis of the dividing cell is perpendicular to the surface, or at an angle of more than $20^{\circ}$ to $30^{\circ}$, one of the daughter cells is cut off from the epithelium, and is soon surrounded by epithelial cells making a young follicle.

Allen and Atcheson ('24) reported that, in the mouse, pregnancy severely inhibited postpubertal oogenesis. They observed fow mitoses in the germinal epithelium of the pregnant animals in comparison with the number observed in the nonpregnant mice near the time of oestrus.

Papanicolaou ('24) confirmed the results of Allen and Atcheson in his work on the guinea pig. He considered oogenesis as a continuous proliferation of oocytes from the germinal epithelium from the time of gonadal differentiation to the time of cessation of sexual activity, though the process was modified by seasonal conditions.

Cowperthwaite ('25) used the occurrence of meiotic phases as a distinguishing criterion for definitive oocytes. From her study of ovaries from rats ranging from newly-born to sexually mature animals, she concluded that young follicles represented a retarded growth condition and not a new formation. She reached this conclusion since she did not find meiotic stages in the germinal epithelium of any ovaries studied.

Contrary to the work of Cowperthwaite, Butcher ('27) found, from his study of the white rat, definite evidence that the germinal potentiality of the peritoneum is not lost at 
puberty. Butcher states that the formation of germ cells from the germinal epithelium continues to take place until fecundity is lost at old age. He reported that a notable increase in mitotic activity in the epithelium was evident during oestrous, and cells enlarging in the epithelium were usually more common at the approach of oestrus.

Hartman ('26) reported that in the opossum the epithelium of the ovary remains active throughout the reproductive period of the animal. He is of the opinion that the ova are produced in strands from the epithelium and not singly as in the mouse. A detailed account of his work has not been published.

The work of Hargitt ('30) confirms the results of Butcher. From his study of adult rat ovaries during different phases of the reproductive cycle, he found that some new ova are produced from the germinal epithelium during pregnancy, but that the epithelium is most active between oestrous periods.

Heys ('31) concluded from her regeneration studies on the ovaries of rats that there was no evidence to support a belief that ova originate from a peritoneal source.

Stockard's investigation of the cyclical activity in the ovary of the prairie dog ('36) supports the view that new ova arise from the ovarian epithelium during sexual maturity. His study indicates that groups of similar epithelial cells invade the cortex of the ovary before the spring period of activity of the animal and that each group of cells usually differentiates into an ovum and its granulosa cells.

One of the more recent contributions that has been made pertaining to the origin of ova is that of Allen and Creadick ('37). They observed numerous mitoses in the germinal epithelium of mice ovaries during oestrus by which new ova were probably added to the cortex.

A similar contribution has recently been made by Guthrie and Jeffers ('38) in their work on adult bats. Their work shows that oocytes are formed from the germinal epithelium of the ovary during sexual maturity. 


\section{ACKNOWLEDGMENTS}

I wish to acknowledge my indebtedness to Dr. Ola Johnston, of North Texas State Teachers College, for criticism of the work, and also to Dr. P. O. Okkelberg, of the University of Michigan, for helpful suggestions.

\section{MATERTALS AND METHODS}

The material used in this investigation consisted of ovaries from thirty-two sexually mature opossums collected in the vicinity of Denton, Texas. The average weight of the adults was $1,800 \mathrm{gms}$. with a range from 1,221 to $2,020 \mathrm{gms}$. Numerous embryos and young which varied in length from 8.1 (headrump) to $53.5 \mathrm{~mm}$., were collected with the adults.

Collection of the material was begun October 1, 1937, and a specimen was collected every week until the latter part of December. From this on animals were collected at short intervals until after the breeding season which was completed in February. Subsequently, specimens were collected at greater intervals until the end of August. Living specimens were brought into the laboratory, killed, weighed, and the ovaries removed. Most of the ovaries were fixed in Bouin's fluid to which 2\% urea crystals had been added. Carnoy's and Flemming's fixing fluids were also used; however, Bouin's solution seemed to give the best fixation. The tissue was cut in serial sections from 4 to 10 micra in thickness and stained with Heidenhain's iron hematoxylin, followed in most cases by eosin as a counterstain.

\section{OBSERVATIONS}

Specimen collected October 15, weight $1999 \mathrm{gms}$. The animal collected on this date was in the anestrous period, which is known to be during October, November and December (Hartman, '23). The uteri and oviducts were of small size, collapsed and showed a low blood supply. Examination of the ovaries revealed that there was no mitotic activity in the germinal epithelium and no young ova in the tunica albuginea beneath the epithelium. A few older follicles were visible deeper in 
the cortex, but the ovary consisted primarily of scar tissue and of old follicles which had apparently undergone degeneration (fig. 1).

Specimen collected October 31, weight 1,950 gms. Numerous young follicles were observed just beneath the germinal epithelium of the ovaries, particularly in the region of the hilus (figs. 2 and 3). Several degenerate follicles were observed deeper in the cortex. No intermediate follicles were visible.

Specimen collected November 19, weight 2,130 gms. The ovaries exhibited several germinal epithelial cells enlarging in situ (fig. 4). The epithelium was proliferating cells in restricted areas, but the enlarged cells were most numerous near the hilus (fig. 5). In the tunica albuginea several enlarged cells were found with follicular cells encircling them. Still deeper in the stroma there were various stages of developing follicles.

Specimen collected December 12, weight 1,618 gms. Although this specimen was comparatively small, the ovaries contained a few follicles which appeared to be almost ready for ovulation. A few mitotic stages were observed in the germinal epithelium (fig. 6). Also, there were several enlarged cells just beneath the epithelial layer in the tunica albuginea (fig. 7).

Specimen collected January 3, weight 2,096 gms. This was the first specimen collected which showed an enlargement of the genital tract and an increased blood supply leading to it. Histological examination of the ovaries revealed that the germinal epithelium was still very active in producing enlarged cells, and especially in the region near the hilus as observed in other specimens.

Specimens collected January 11 to January 18, weight 1,980, 2,079, and 1,985 gms. respectively. The uteri of these were somewhat congested with blood and the entire reproductive tracts were greatly enlarged. The ovaries were enlarged and they exhibited prominent mature follicles which resembled blisters protruding from the surface. These were apparently 
ready for ovulation (fig. 8). A few enlarged cells were observed in the germinal epithelium.

Specimen collected January 28 , weight 1,987 gms. This was the first pregnant specimen collected. Twenty gastrula stages were found in the folds of the two uteri. The ovaries contained atretic follicles and corpora lutea in the process of formation (fig. 9). In this and in other animals in which ovulation had occurred, the basement membrane was easily observed in the empty follicles sharply differentiating them from the theca interna. No new germ cells seemed to be forming in the germinal epithelium, but a few young follicles were observed in the tunica albuginea just beneath the epithelium.

Specimen collected February 8, weight 1,790 gms. Three embryos $21.1 \mathrm{~mm}$. in length were found in the pouch of this aduit. A few enlarged cells were visible in the germinal epithelium in restricted areas especially near the hilus. A few atretic follicles and numerous corpora lutea were present (fig. 10).

Specimen collected March 31, weight 1,302 gms. This small female had eight embryos $53.5 \mathrm{~mm}$. long in her pouch. Several atretic follicles were found in the ovaries and what appeared to be corpora lutea in process of degeneration. Only a few enlarged cells were observed in the germinal epithelium, but numerous young follicles were present in the tunica albuginea.

Specimen collected June 6, weight 1,840 gms. Six embryos $43 \mathrm{~mm}$. in length were found in the pouch. This was probably the second litter of the year for this animal. Hartman ('23), has shown that the second breeding period begins about 3 months after the onset of the first breeding period. The ovaries were practically filled with degenerate follicles and several corpora lutea were observed. The germinal epithelium showed no proliferating activity and no mitotic figures were present, but a few young follicles still remained deep in the cortex.

Specimen collected July 15, weight 2,001 gms. No young were found in the pouch of this specimen, but the mammary glands were enlarged and contained milk, giving evidence that 
she was still suckling her young. The ovaries were somewhat reduced in size, and exhibited numerous empty follicles and a few corpora lutea. No enlarged cells were observed in the germinal epithelium or tunica albuginea, and only a very limited number of young follicles were present deep in the cortex of the ovary.

Specimen collected August 3, weight 1,620 gms. The ovaries of this specimen were typical of three animals collected during the month of August. A few young follicles remained in the deeper part of the cortex, and numerous atretic follicles were present in the deeper part of the ovary (fig. 11). No activity was visible in the germinal epithelium and no young ova were found in the tunica albuginea. In general, the condition of the ovary was like that of the specimens collected during the month of October.

\section{FORMATION OF OVA}

In the adult opossum there seems to be two methods by which new ova are produced in the ovaries. Firstly, single cells of the germinal epithelium enlarge in situ and become separated from the epithelial layer of cells by migrating into the tunica albuginea. Here each cell becomes surrounded by smaller epithelial cells and forms a young follicle. Secondly, mitotic division of epithelial cells may produce cells which lie just beneath the germinal epithelium. The latter may then form follicles by becoming surrounded by smaller adjacent cells. However, the first mentioned method seems to be the most common.

Figure 4 shows a typical germinal epithelial cell enlarged in situ. In this and in other cases it can be shown that the enlarged cells represent typical cells of the surface layer which have increased in size and assumed a more spherical form. Intermediate stages may be found between the flattened epithelial cells and the large spherical ones. After assuming the spherical form, the enlarged cells leave the epithelial layer and sink into the tunica albuginea where they are encircled by flattened and elongated cells which have also prob- 
ably been derived from the epithelium (fig. 7). Often several cells appear to enlarge in one region in the germinal epithelium and these move in groups into the tunica albuginea. This grouping is particularly evident in the region near the hilus of the ovary (fig. 5).

A typical telophase stage is shown in figure 6 . The spindle is located almost perpendicularly to the surface of the ovary and thus a daughter cell will be contributed to the underlying tissue. A cell contributed in this manner may be destined to become an ovum since it is enlarged and similar to a cell which moves from the epithelium without division, or it may become a follicle cell. It appears that only a few ova are contributed in this manner.

It was found that very few oocytes and young follicles were present at the beginning of the anoestral period. Within a few weeks the number increased, reaching a maximum before the onset of the breeding season. After pregnancy, the number of oocytes decreased rather rapidly until only a very few were present in the ovaries at the end of the breeding season. This decrease is due to a cessation in the formation of new ova, and to the loss through ovulation of those already developed. However, a few ova continue to form during pregnancy and throughout the breeding season. There is a correlation between the activity of the germinal epithelium and the increase in numbers of oocytes. When the number of oocytes is smallest, as at the close of the breeding period, the germinal epithelium is least active; when the number of oocytes is greatest, as in the latter part of the anoestral period, more cases of enlarged and ingrowing groups of germinal epithelial cells are found.

\section{DISCUSSION}

The results of this investigation seem to substantiate the concept that the germinal potentiality of the mammalian ovary is continued throughout the reproductive period of the animal. Arai ('20), Allen ('23), Allen and Atcheson ('24), Papanicolaou ('24), Butcher ('27), Hargitt ('30), Stockard ('36), Allen and Creadick ('37), Guthrie and Jeffers ('38), and 
others have found this condition in the forms they studied. Evidence indicates that the germinal epithelium of the opossum ovary continues to be active during adult life, but one cannot estimate how many of these cells will become functional ova. Papanicolaou ('24) observed that in the guinea pig ingrowing groups of epithelial cells might form ova, interstitial cells, follicle cells, or luteal cells. In the present investigation no attempt has been made to determine the destiny of all the cells which had their origin in the germinal epithelium, but it is only reasonable to believe that many of them did not form ova. League and Hartman ('25) state that the presence of anovular follicles in the opossum ovary is due to an ingrowth of epithelial cells which fail to become associated with ova.

Hargitt ('30) described two methods by which new ova are produced in the adult rat. One of these methods is by enlargement in the germinal epithelium of cells which become surrounded by smaller neighboring cells, and move into the tunica albuginea to form a young follicle. In the other method described, a number of germinal epithelial cells round up into a mass and move into the albuginea, where one of the cells may enlarge to form an ovum. The rest of the cells remain small and form follicle cells. The first method is similar to that described in the opossum. This observation conforms with results obtained by Guthrie and Jeffers ('38) in their work on adult bat ovaries. Their studies indicate that oocytes are formed during sexual maturity by the movement of enlarged cells from the germinal epithelium into the underlying tissue. Several investigators mention only one method by which ova are formed in the adult and that is by mitotic division of cells in the germinal epithelium. Allen ('23), Allen and Atcheson ('24), Butcher ('27), and Allen and Creadick ('37), have concluded from their studies that new ova arise in the adult by mitosis of cells in the epithelium. In the opossum it appears that a few ova arise in this manner, but the number is very small in comparison with the number which 
migrate by the enlargement of the germinal epithelial cells in situ and subsequently migrate into the cortex.

The fact that there is a correlation between the number of oocytes present in the adult ovaries and the activity of the germinal epithelium is further proof that the enlarged and dividing cells of the epithelium form new ova. Hargitt (' 30 ), found a correlation between the number of enlarged cells in the germinal epithelium and the number of ova in the ovaries of adult rats. He calls attention to the fact that many investigators have failed to observe this because the enlarged cells in the epithelium are often very difficult to distinguish.

The observation that the activity of the germinal epithelium is not uniform over the entire ovary was easily made in most of the specimens used in this investigation. Papanicolaou ('24) observed this lack of uniformity in his study of guinea pig ovaries. Hartman ('26), in his brief report of postpubertal oogenesis in the opossum, states that the activity of the ovary is confined to a circumscribed area on each side of the hilus. From the present study it is also evident that the greatest proliferation is shown by the epithelium near the hilus, but it is by no means confined to this area. The suggestion made by Papanicolaou that the increased activity in the region of the hilus is due to a greater supply of blood in that region seems to be a valid one.

With regard to the seasonal production of new ova, the present results are comparable to those obtained by Allen ('23), Allen and Atcheson ('24), Papanicolaou ('24), Butcher ('27), Hargitt ('30), and Allen and Creadrick ('37). Hartman ('23) found that in Texas the breeding season of the opossum begins in January following a 3-months anoestrous period. He reported that a first brood is weaned in about 3 months and immediately following, most of the females become pregnant again. Thus, a second litter would be at the weaning stage about July or August. Using these results as a basis, collection of the material was begun in October. The first specimens showed no indication of epithelial activity, but the animal col- 
lected October 31 exhibited numerous young ova just beneath the germinal epithelium. However, only a few enlarged cells were observed in the epithelium. Specimens collected after October 31 showed a great activity of the germinal epithelium until the approach of pregnancy. Pregnancy seemed to have a marked inhibiting effect upon the production of ova, but the process did not cease until after the second breeding period which was about the first of June. From the data herein presented, it seems that the ovary of the opossum undergoes a period of rest during the months of July, August and September, which accounts for the absence of young ova and follicles during that time.

Since the described formation of ova in the adult applies to the opossum, one of the lower mammals, as well as to such higher mammals as the rat, mouse, bat, and guinea pig, it is suggestive that we are dealing with a general mammalian process.

\section{SUMMARY AND CONCLUSIONS}

1. New ova are formed in the germinal epithelium during the adult life of the opossum.

2. There is a correlation between the activity of the germinal epithelium and the number of oocytes and young follicles present in the ovaries.

3. A few new ova are produced from the germinal epithelium of ovaries during pregnancy and oestrus, but it is in the ovaries of nonpregnant animal near the close of the anoestrous period that the germinal epithelium is most active.

4. The majority of new ova have their origin from germinal epithelial cells which enlarge in situ and subsequently move into the tunica albuginea.

5. Mitosis of cells in the germinal epithelium, whose axes are directed perpendicularly to the surface of the ovary, contribute a few new ova.

6. The germinal epithelium near the hilus of the ovary is most active in producing new ova. 


\section{LITERATURE CITED}

Allex, Edank 1923 Ovogenesis During Sexunl Maturity. Am. J. Anat., vol. 31. pp. 439-482.

Allex, Edgar, and Bellfield Ateheson 1924 The Effect of Pregnaney upon Postpubertal Ovogenesis. Anat. Ree., vol. 27, pp. 178-196.

Allex, Edgar, and R. N. Creadick 1937 Ovogenesis During Sexual Maturity. Anat. Rec., vol. 60, pp. 191-195.

Arar, Hoyato 1920 On the Postuatal Development of the Ovary (albino rat) with Especial Reference to the Number of Ova. Am. J. Anat., vol. 27, pp. 405-462.

Butrener, EARL O. 1927 The Origin of the Definitive Ova in the white Rat. (Mus norvegicus albinus). Am. J. Anat., vol. 37, pp. 13-30.

Cowphrthwaine, Marion Hazel 1925 Observations of Pre- and Post-pubertal Oogenesis in the White Rat. (Mus norvegicus albinus). Am. J. Anat., vol. 36, pp. 69-90.

Gitilim, Mary J., AND Katharine R. JFiners 1938 A Cytological Study of the Ovaries of the Bats Myotis lueifugus lucifugus and Mrotis griesescens. J. Morpl. and Physiol., vol. 62, pp. 523-556.

Ilargi't', Grokge T. 1930 The Formation of the Sex Glands and Germ Cells of Mammals. V. Germ Cells in the Ovaries of Adult, Pregnant, and Senile Albino Rats. J. Morph. and Physiol., vol. 50, pp. 453-469.

Trarpman, C. G. 1923 The Breeding Season of the Opossum. J. Morph, and Physiol., vol. 40, pp. 142-215.

1926 Postpubertal Oogenesis in the Opossum. Anat. Rec., vol. 32 , p. 209.

Hevs, Florence 1931 The Probiem of the Origin of Germ Cells. Quart. Rev. Biol., vol. 6, pp. 1-45.

Ijeague, Bessie, and C. G. Hakrman 1925 Anovular Graafian Follicles in Mammalian Ovaries. Anat. Ree., vol. 30, pp. 1-14.

Paranicoraou, Grorge N. 1924 Ovogenesis During Sexual Maturity as Elucidated by Experimental Methods. Proc. Soc. Exper. Biol. and Med., vol. 21, pp. 393-396.

Stockard, Alfred H. 1936 Studies on the Female Reproductive System of the Prajric Jog, Cynomys leucurus. II. Normal Cyclic Phenomena of the Ovarian Follicles. Pap. Mich. Acad. Science Arts and Letters. Vol. 22 , pp. $671-690$.

\section{PT,ATE 1}

EXPIAANATION OF FIGLRES

1. Longitudinal section through tho ovary of a specimen collected October 15 .

2 I.ongitudinal section throngh the ovary of a specimen collected October 31 .

3 Magnification of the hilar region of the ovary shown in figure 2.

4 Ovarian epithelium and tumica of specimen collected November 19. 
ORIGIN OF OVA IN OPOSSLM

PLATE 1

N. B. EVERETT
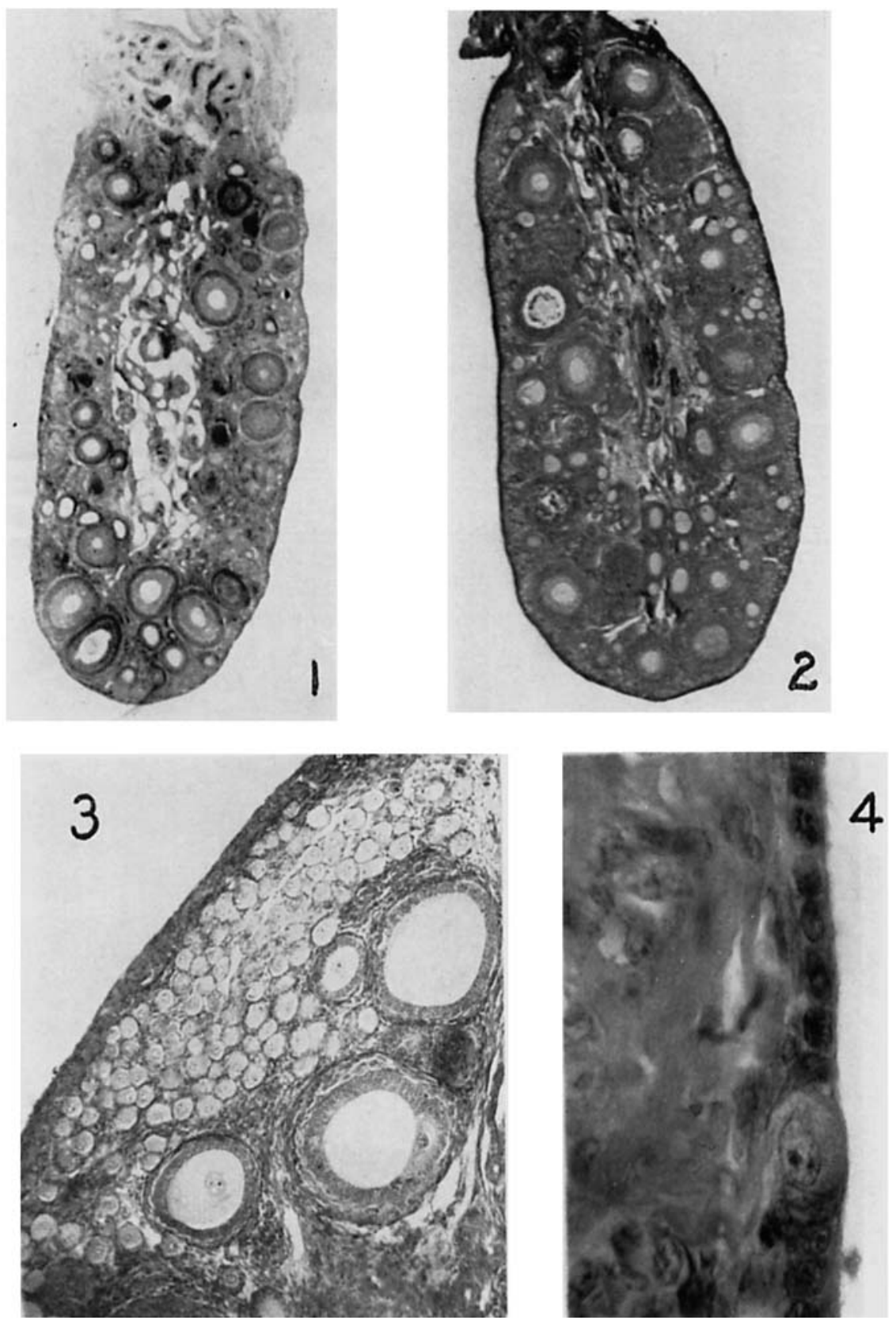
v. B. RVELETT
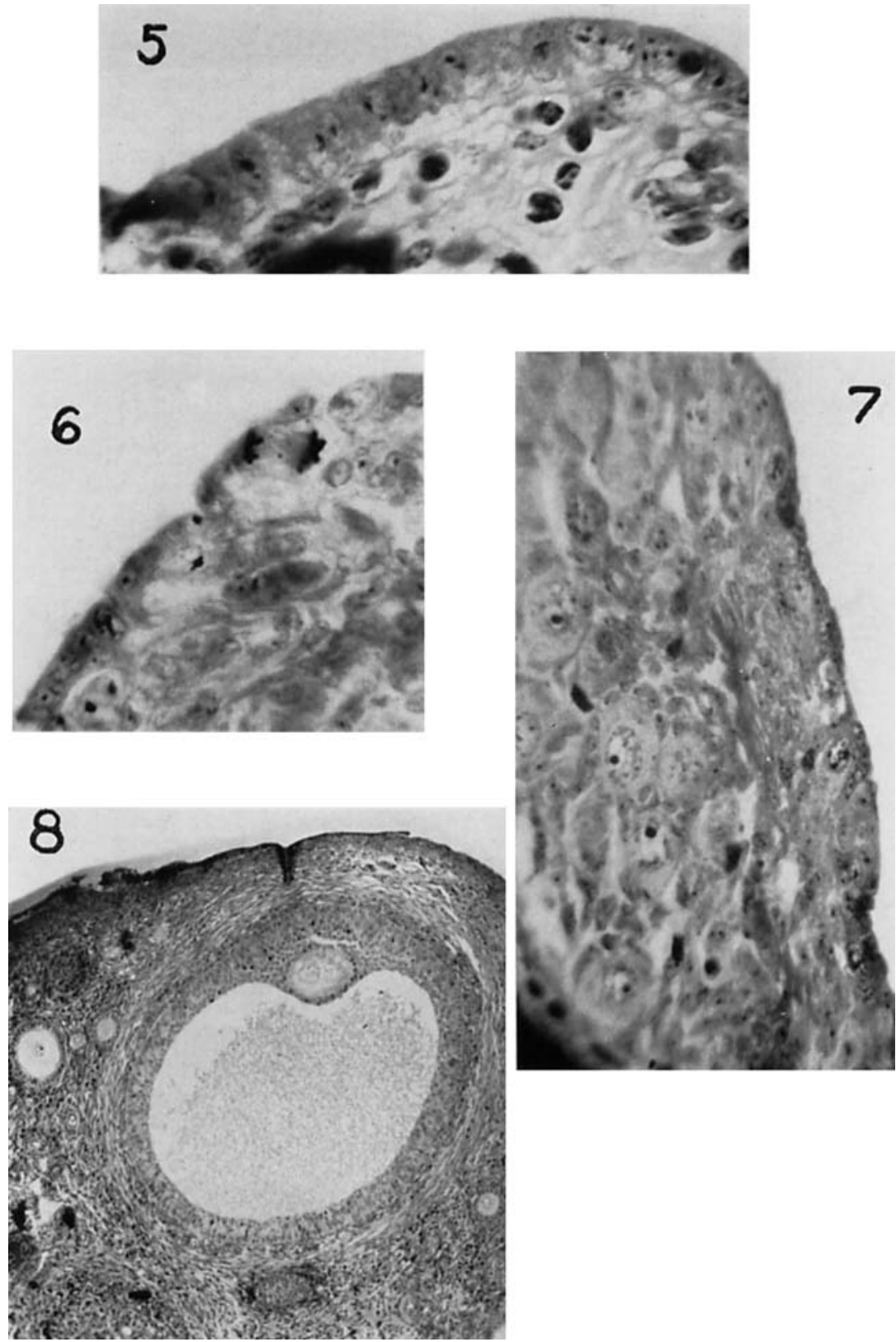

5 Hilar epithclium of speeimen collected November 19.

6 Epithelial cell in telophase stage of mitosis.

7 Numerous young follicles in the cortical portion of the ovary.

8 Follicle nearing maturity. 

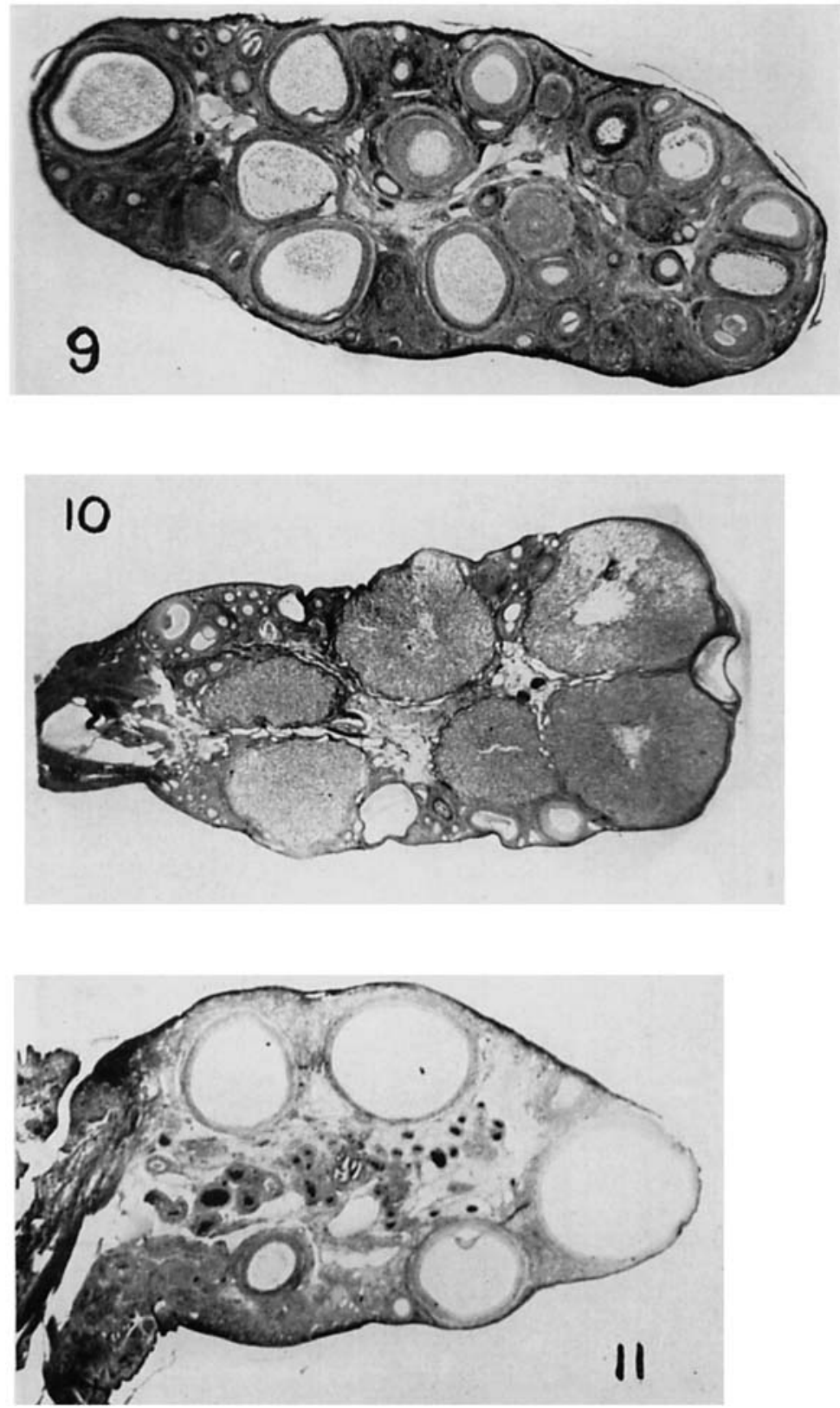

9 Longitudinal section of ovary from specimen in an carly stage of preguaney.

10 Section of ovary from specimen in later pregnaney.

11 Section of ovary from specimen collected after the young were weaned. 